\title{
The Effect of Acute and Chronic Ethanol Intake on Hepatic Glycerolipid Biosynthesis in the Hamster
}

\author{
Robert G. Lamb, Craig K. Wood, and Harold J. Fallon, Departments of \\ Pharmacology and Medicine, Medical College of Virginia, \\ Richmond, Virginia 23298
}

A в S T R A C T The effect of acute and chronic ethanol intake on hepatic glycerolipid biosynthesis in the hamster was studied by in vivo and in vitro techniques. The results were compared with those from control hamsters receiving isocaloric amounts of glucose.

Both chronic and acute ethanol intake elevated serum and hepatic triglyceride concentrations and induced a rapid rise in the capacity of neutral glycerolipid formation from $s n\left[1,3-{ }^{14} \mathrm{C}\right]$ glycerol-3-phosphate by hamster liver homogenate and microsomal fractions. Ethanol intake also produced a corresponding increase in the incorporation of $\left[1,3-{ }^{14} \mathrm{C}\right]$ glycerol into hepatic neutral glycerolipids by the intact animal.

The ethanol-induced rise in the capacity of neutral glycerolipid production by liver as measured in vivo and in vitro correlated well with an increase in hepatic phosphatidate phosphohydrolase activity. Therefore, the rise in hepatic and serum triglyceride levels associated with ethanol intake may be explained in part by an increase in the activity of this enzyme.

\section{INTRODUCTION}

Ethanol intake in man (1-3) and experimental animals $(3-7)$ is associated with a rise in serum and liver triglyceride levels. Hypertriglyceridemia during ethanol intake has been attributed to reduced plasma triglyceride clearance $(3,6,8)$ or to a rise in hepatic triglyceride $(5,6,9-15)$ and very low density lipoprotein production $(3,6)$. The mechanism of the increase in hepatic triglyceride biosynthesis during ethanol ingestion is not clear. Elevated hepatic levels of fatty acids (3, $10,16)$ and $s n$-glycerol-3-phosphate $(3,7,9,17,18)$ during ethanol consumption may contribute to the rise in hepatic glycerolipid biosynthesis. Alternatively,

A preliminary report of this research was presented on 4 April 1977 in Chicago, Ill., at the annual meeting of the Federation of American Societies for Experimental Biology.

Received for publication 24 February 1978 and in revised form 15 September 1978. enhanced activity of various enzymatic reactions in hepatic glycerolipid biosynthesis during ethanol intake could accelerate hepatic triglyceride formation (10-15). The latter possibility was evaluated in these studies by measuring the rate of hepatic triglyceride formation in vivo and in vitro after acute and chronic ethanol intake in the hamster.

\section{METHODS}

Materials. All lipids used for thin-layer chromatography standards were obtained from Applied Science Labs, Inc. (State College, Pa.). Coenzyme A, palmitate, ATP, $\mathbf{M g C l}_{2}$, EDTA, L-glycerol-3-phosphate, and Tris- $\mathrm{HCl}$ were secured from Sigma Chemical Co. (St. Louis, Mo.). EGTA was obtained from Eastman Kodak Co. (Rochester, N.Y.). Fatty acid poor albumin (Fraction V) was obtained from Pentex Biochemical (Kankakee, Ill.) and $s n\left[1,3-{ }^{14} \mathrm{C}\right]$ glycerol-3-phosphate and $\left[1,3-{ }^{14} \mathrm{C}\right]$ glycerol were purchased from New England Nuclear (Boston, Mass.).

Experimental procedure. Groups of male Golden Syrian hamsters (four to six animals) weighing 90-100 g were used in these studies because this rodent readily consumes ethanol. In the chronic ethanol experiments ( $1-6 \mathrm{wk})$, three groups of animals received one of the following diets. One group (ethanol) had free access to chow and drinking water that contained $20 \%$ ethanol (wt/vol). Another group (carbohydrate) received glucose in drinking water and chow that was isocalorically equivalent to the ethanol and chow consumed by the ethanol group. The third group (control) was given water and chow ad lib. The chow intake of each group was measured in these experiments, and the control group consumed a significantly larger amount than the other two. Total caloric intake for each group was similar and ranged from 29-32 calories/day per $100 \mathrm{~g}$ body wt. There was no significant difference in the weight gained by each animal group. Ethanol and glucose comprised $40-50 \%$ of the caloric intake in the appropriate dietary group. The liquid diets described by Thompson and Reitz (19) for rats were inappropriate because the hamsters refused to ingest them. However, hamsters readily ingest the alcohol-water mixture. In the acute ethanol experiments, the experimental and control groups were given by oral intubation aliquots of a $50 \%(\mathrm{wt} / \mathrm{vol})$ absolute ethanol or $87.5 \%(\mathrm{wt} / \mathrm{vol}$ ) glucose water solution to produce a dose of 5 or $8.75 \mathrm{~g} / \mathrm{kg}$ body wt of ethanol or glucose, respectively. In some acute experiments a group of animals received a volume of water equivalent to the liquid administered to the glucose- and 
ethanol-treated animals. All animals in the acute studies were fasted after receiving the oral dose of glucose, ethanol, or water.

The incorporation of intraperitoneally administered [1,3${ }^{14} \mathrm{C}$ ]glycerol $(2.5 \mu \mathrm{Ci})$ into hepatic glycerolipids was determined as previously outlined $(20,21)$ except that the animals were sacrificed $30 \mathrm{~min}$ after the injection of labeled glycerol, when radioactivity was maximum in liver triglyceride. The time-course of hepatic triglyceride formation from $\left[1,3-{ }^{14} \mathrm{C}\right]$ glycerol was similar to that reported by Adams et al. (20) for rat liver.

Liver homogenates and microsomes were prepared in $0.225 \mathrm{M}$ sucrose containing $2.5 \mathrm{mM}$ EDTA and $0.05 \mathrm{M}$ Tris- $\mathrm{HCl} \mathrm{pH} 7.5$ as described previously for rat liver (22). The standard incubation mixture $\left({ }^{*}\right)$, which was optimum for measuring the incorporation of $\mathrm{sn}-\left[1,3-{ }^{14} \mathrm{C}\right]$ glycerol-3phosphate into glycerolipids, contained $30 \mathrm{mM}$ Tris- $\mathrm{HCl}$ pH 8.0, 3.3 mM $\mathrm{MgCl}_{2}, 0.70 \mathrm{mM}$ dithiothreitol, $25 \mu \mathrm{M}$ coenzyme A, $1.6 \mathrm{mM}$ ATP, $0.60 \mathrm{mM}$ ammonium palmitate, $0.6 \mathrm{mM}$ sn $\left[1,3-{ }^{14} \mathrm{C}\right]$ glycerol-3-phosphate $(0.1 \mu \mathrm{Ci}), 1.25 \mathrm{mg}$ albumin, and $0.3 \mathrm{mg}$ of microsomal or homogenate protein in a total volume of $0.35 \mathrm{ml}$. Glycerolipid formation was initiated by the addition of cellular protein. Homogenate and microsomal incubations were terminated after 15 and 20 min at $37^{\circ} \mathrm{C}$ in a shaking water bath by the addition of 3 $\mathrm{ml}$ of $1: 2$ (chloroform-methanol) containing $1 \% \quad 1 \mathrm{~N} \mathrm{HCl}$. Lipids were extracted, separated into neutral lipid and phospholipid fractions by column chromatography $(21,22)$, and individual compounds identified by thin-layer chromatography as previously described (21-25).

Total lipid formation (neutral lipid plus phospholipid) during the standard incubation $\left(^{*}\right)$ was used as a measure of $s n$-glycerol-3-phosphate acyltransferase activity. Enzymatic reaction rates determined with this technique (Table II) in liver microsomes isolated from hamsters exposed to isocaloric amounts of ethanol and glucose for $1 \mathrm{wk}$ were similar to that observed when palmitoyl coenzyme $A(C o A)^{1}$ replaced ATP, CoA and palmitate in the incubation mixture (21). However, the acyl CoA-generating system had several advantages: $(a)$ the continual production of substrate permitted longer incubation periods; (b) labeling of neutral lipids was greater; $(c)$ the detergent effect of micellar levels of long-chain acyl CoA derivatives was prevented.

The ratio of neutral lipid (diglyceride plus triglyceride) to phospholipid (lysophosphatidate $10-20 \%$ plus phosphatidate $80-90 \%$ ) formed in the usual incubation was used to estimate phosphatidate phosphohydrolase activity. A more direct measure of phosphatidate phosphohydrolase activity used membrane-bound phosphatidate as substrate rather than an aqueous dispersion of phosphatidic acid. The membrane-bound substrate was chosen because it is unlikely that an aqueous dispersion of phosphatidate exists intracellularly. Microsomal-bound phosphatidate was formed by substituting $3.3 \mathrm{mM} \mathrm{CaCl}$ for $\mathrm{MgCl}_{2}$ in the standard incubation mixture $(*)$ of glycerolipid formation. This caused phosphatidate to accumulate because $\mathrm{Ca}^{2+}$ inhibits and $\mathrm{Mg}^{2+}$ is required for hepatic microsomal phosphatidate phosphohydrolase activity (25). Although $\mathrm{Ca}^{2+}$ inhibited phosphatidate phosphohydrolase activity (25), it substituted for $\mathrm{Mg}^{2+}$ in the formation of long-chain fatty acyl CoA compounds by thiokinase. After an initial incubation of $20 \mathrm{~min}$, $1.5 \mu \mathrm{mol}$ of EGTA $(0.05 \mathrm{ml})$ was added and $30 \mathrm{~s}$ later $1 \mu \mathrm{mol}$ of $\mathrm{MgCl}_{2}(0.05 \mathrm{ml})$ was also added to the mixture and the reaction continued an additional $10 \mathrm{~min}$. Neutral lipid formation was linear throughout the 10 -min time period. Phos-

${ }^{1}$ Abbreviation used in this paper: CoA, coenzyme A. phatidate phosphohydrolase activity was also measured in the $105,000 \mathrm{~g}$ supernate and the fraction of supernate precipitated by $40 \%$ saturated $\left(\mathrm{NH}_{4}\right)_{2} \mathrm{SO}_{4}(25)$. This was accomplished by incubating the standard incubation mixture with microsomes for $20 \mathrm{~min}$ before adding supernatant protein and continuing the incubation for an additional 10min period. The neutral lipid formed in the absence of supernatant protein was subtracted from the supernatant incubations to correct for microsomal neutral lipid formation. All incubations were terminated and lipids extracted and identified as described above. Neutral lipid formation (primarily diglyceride) during the second incubation period (10 min) was used to estimate microsomal and supernatant phosphatidate phosphohydrolase activity. These techniques for determination of microsomal and supernatant phosphatidate phosphohydrolase gave results similar to those obtained with other techniques previously described by this laboratory $(21,25,26)$.

Liver triglyceride concentrations were measured as described by Haux and Natelson (27). Homogenate and microsomal protein levels were determined as outlined by Lowry et al. (28).

\section{RESULTS}

Table I shows the effect of acute $(3$ and $20 \mathrm{~h})$ and chronic ( 1 and $6 \mathrm{wk}$ ) ethanol and glucose intake on serum and hepatic triglyceride concentrations. At all time periods, serum triglyceride levels were approximately twofold higher in animals receiving ethanol when compared with those given an isocaloric amount of glucose. However, hepatic triglyceride content showed only a modest increase after either acute or chronic ethanol ingestion. Groups of male Sprague-Dawley rats given ethanol or glucose under these same conditions showed similar changes in serum triglyceride content.

Ethanol-induced increases in hepatic and serum triglyceride levels may have resulted from a rise in the rate of hepatic triglyceride biosynthesis. Therefore, studies were conducted to measure the incorporation of intraperitoneally administered $\left[1,3-{ }^{14} \mathrm{C}\right]$ glycerol into hepatic neutral lipids at different periods after acute (Fig. 1) and chronic (Fig. 2) ethanol intake. Fig. 1 indicates that hamsters given a single dose of ethanol $(5 \mathrm{~g} / \mathrm{kg})$ showed a rapid, but brief, rise in hepatic neutral lipid formation in vivo, when compared with controls administered an isocaloric amount of glucose $(8.75 \mathrm{~g} / \mathrm{kg})$. However, chronic ethanol administration (Fig. 2) produced a sustained increase in hepatic neutral lipid production from $\left[1,3-{ }^{14} \mathrm{C}\right]$ glycerol. The ethanol-induced increase in hepatic triglyceride production associated with acute ethanol administration could result from increased fatty acid production if fatty acid oxidation were decreased and esterification was nonlimiting. One report suggests that ethanol intake does not increase hepatic fatty acid synthesis (18), although acute ethanol ingestion may increase serum free fatty acids. Alternatively, ethanol intake could induce an increase in the capacity of liver to 
TABLE I

Effect of Acute and Chronic Ethanol Intake on Serum and Hepatic Triglyceride Concentrations

\begin{tabular}{ccc}
\hline & \multicolumn{2}{c}{ Triglyceride } \\
\cline { 2 - 3 } Exposure* & Serum & Liver \\
\hline & $m g / 100 \mathrm{ml} \pm$ SEM & $m g / \mathrm{g} \pm$ SEM \\
Ethanol, $3 \mathrm{~h}$ & $147 \pm 26 \ddagger$ & $5.5 \pm 0.5$ \\
Glucose, $3 \mathrm{~h}$ & $82 \pm 10$ & $5.0 \pm 0.2$ \\
Ethanol, $20 \mathrm{~h}$ & $213 \pm 19 \S$ & $10.7 \pm 1.0 \S$ \\
Glucose, $20 \mathrm{~h}$ & $80 \pm 9$ & $5.8 \pm 0.8$ \\
Ethanol, $1 \mathrm{wk}$ & $123 \pm 12 \ddagger$ & $7.8 \pm 0.2 \ddagger$ \\
Glucose, $1 \mathrm{wk}$ & $82 \pm 3$ & $6.0 \pm 0.5$ \\
Ethanol, 6 wk & $131 \pm 20 \ddagger$ & $10.6 \pm 0.8 \ddagger$ \\
Glucose, 6 wk & $61 \pm 9$ & $7.7 \pm 0.6$ \\
\hline
\end{tabular}

* Each group contains (four to five) hamsters. See Methods for a description of the administration of ethanol and glucose in the acute ( 3 and $20 \mathrm{~h}$ ) and chronic ( 1 and $6 \mathrm{wk}$ ) dietary experiments.

$\ddagger P \leq \mathbf{0 . 0 5}$ level of significance from glucose control.

$\S P \leq 0.01$ level of significance from glucose control.

esterify fatty acids and form neutral lipids. If correct, changes in the biosynthetic pathway of neutral lipid formation would be anticipated during ethanol ingestion. The enzymes in this pathway include glycerol-

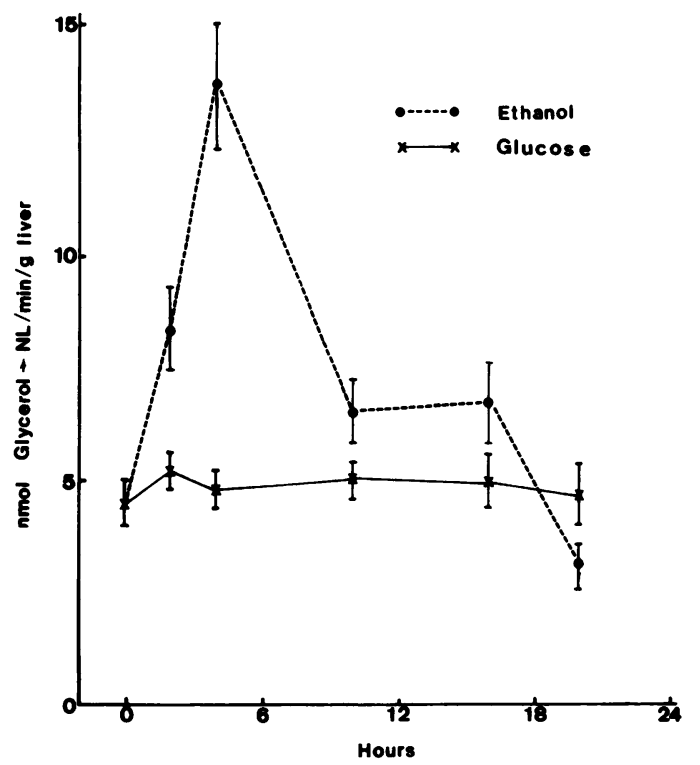

Figure 1 The incorporation of intraperitoneally administered $\left[1,3-{ }^{14} \mathrm{C}\right]$ glycerol into liver neutral (NL) glycerolipids in hamsters receiving a single dose of ethanol (5 $\mathrm{g} / \mathrm{kg}$ ) or glucose $(8.75 \mathrm{~g} / \mathrm{kg})$ for various time periods. Hamsters were sacrificed $30 \mathrm{~min}$ after receiving labeled glycerol when liver neutral glycerolipid radioactivity was maximum and at a steady state (plateau). Each point represents the mean of four to five animals with the SEM indicated by the brackets. 3-phosphate acyltransferase, lysophosphatidate acyltransferase, phosphatidate phosphohydrolase, and, finally, diglyceride acyltransferase (see Fig. 3).

Table II shows the effect of acute $(3 \mathrm{~h})$ and chronic ( $1 \mathrm{wk}$ ) ethanol or glucose intake on the incorporation of $s n\left[1,3-{ }^{14} \mathrm{C}\right]$ glycerol-3-phosphate into neutral lipid, phospholipid, and total glycerolipids (total) by hamster liver homogenates and microsomal fractions. Total glycerolipid formation was used as a measure of $s n$ glycerol-3-phosphate acyltransferase activity. Inasmuch as maximum lipid production, as measured in vitro, was not elevated by acute or chronic ethanol intake, it seems unlikely that alterations in $s n$ glycerol-3-phosphate acyltransferase activity are responsible for the ethanol-induced rise in hepatic triglyceride production (13). However, ethanol intake did increase hepatic neutral lipid (diglyceride and triglyceride) production and the neutral lipid/phospholipid ratio at all exposure periods. The neutral lipid/phospholipid ratio is an indirect but reliable $(25$, 26) indicator of phosphatidate phosphohydrolase activity. Furthermore, a similar increase in activity was found when microsomal phosphatidate phosphohydrolase activity was measured directly (Table

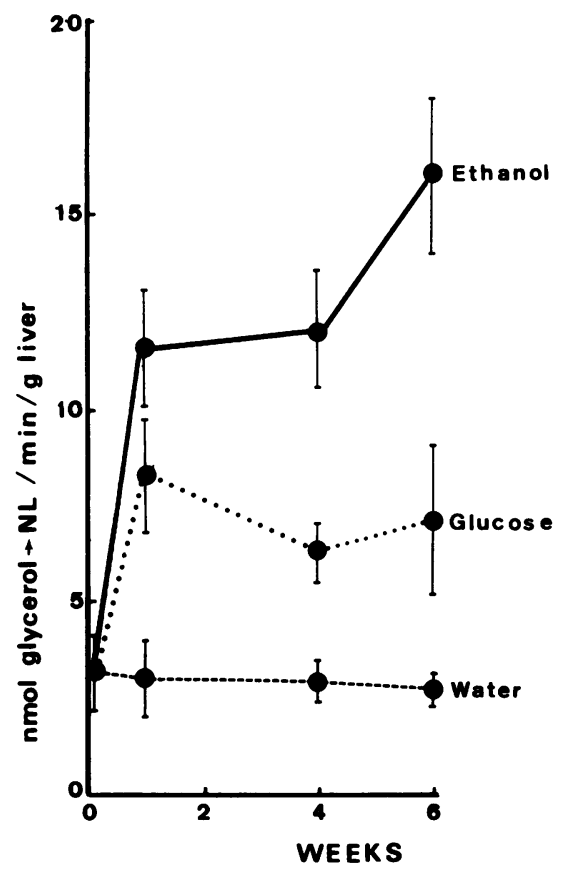

FIGURE 2 The formation of hepatic neutral (NL) glycerolipids from intraperitoneally administered [1,3-14 C]glycerol in hamsters receiving isocaloric amounts of ethanol, glucose, and laboratory chow for various time periods. The watertreated animals consumed more chow so that their total caloric intake was not significantly different from the glucose- and ethanol-treated animals. Each point represents the mean of four to five animals and the brackets indicate the SEM. See the legend of Fig. 1 for a more detailed description of the methodology. 


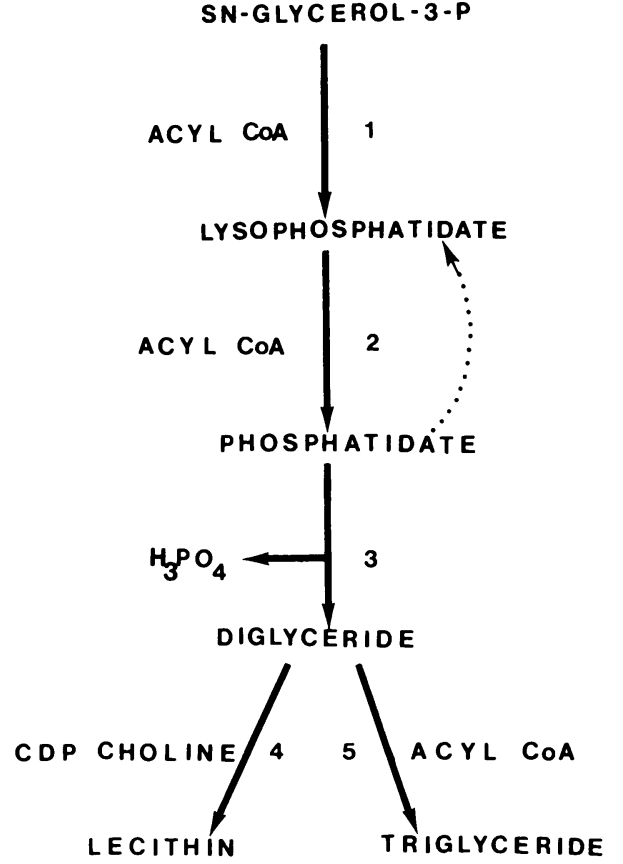

Figure 3 Individual reactions involved in the incorporation of $s n\left[1,3-{ }^{14} \mathrm{C}\right]$ glycerol-3-phosphate into hepatic glycerolipids. The following enzymes are represented: (1) snglycerol-3-phosphate acyltransferase; (2) lysophosphatidate acyltransferase; (3) phosphatidate phosphohydrolase; (4) choline phosphotransferase; (5) diglyceride acyltransferase.

II). Phosphatidate phosphohydrolase activity measured in the $105,000 \mathrm{~g}$ supernate or supernatant fraction precipitated by $40 \%$ saturated $\left(\mathrm{NH}_{4}\right)_{2} \mathrm{SO}_{4}$ also was elevated 138 and $70 \%$ after $4 \mathrm{~h}$ and $1 \mathrm{wk}$ of ethanol exposure, respectively. These results suggested that ethanol intake increases the enzymatic capacity for hepatic neutral lipid production by raising total phosphatidate phosphohydrolase activity.

Fig. 4 shows the time-course of $s n\left[1,3-{ }^{14} \mathrm{C}\right]$ glycerol3-phosphate incorporation into neutral lipids by hamster liver microsomes after acute administration of ethanol $(5 \mathrm{~g} / \mathrm{kg})$ or glucose $(8.7 \mathrm{~g} / \mathrm{kg})$. The rapid rise in the rate of neutral lipid formation after ethanol intake was sustained for 10-12 h. Because the data presented in Table II suggested that increased conversion of phosphatidic acid to neutral lipid occurred during ethanol treatment, microsomal phosphatidate phosphohydrolase activity was measured directly using membrane-bound phosphatidate as substrate after acute ethanol intake. The results demonstrate that phosphatidate phosphohydrolase activity increases in a manner similar to the ethanol-induced rise in neutral lipid production (Fig. 4). The absolute increase in phosphohydrolase activity is greater than the rise in neutral lipid formation shown in Fig. 4 because higher levels of microsomal phosphatidate substrate were used under these incubation conditions. The time-course of the ethanol-induced change in hepatic neutral lipid production as measured in vivo (Fig. 1) and in vitro (Fig. 4) and the rise in microsomal phosphatidate phosphohydrolase activity (Fig. 5) are all similar, supporting the concept that phosphatidate phosphohydrolase activity is an important determinant of hepatic triglyceride production in vivo.

\section{DISCUSSION}

Acute and chronic ethanol intake is associated with a rise in serum and liver triglyceride levels (1-6).

TABLE II

Effect of Acute and Chronic Ethanol Intake on In Vitro Hepatic Glycerolipid Biosynthesis*

\begin{tabular}{lllllll}
\hline \multicolumn{1}{c}{ Cell fraction } & \multicolumn{1}{c}{ Exposure } & \multicolumn{1}{c}{ NL } & \multicolumn{1}{c}{ PL } & Totalt & NL/PL $\$$ & $\begin{array}{c}\text { Phosphatidate } \\
\text { phosphohydrolase" }\end{array}$ \\
\hline Homogenate (5) & Ethanol, 3 h & $0.18 \pm 0.02^{* *}$ & $0.16 \pm 0.01$ & $0.33 \pm 0.02$ & 1.15 & \\
Homogenate (5) & Glucose, 3 h & $0.11 \pm 0.01$ & $0.24 \pm 0.01$ & $0.35 \pm 0.02$ & 0.48 & \\
Microsome (5) & Ethanol, 3 h & $0.34 \pm 0.02 \downarrow$ & $0.48 \pm 0.03$ & $0.82 \pm 0.04$ & 0.71 & $0.74 \pm 0.08 \ddagger \ddagger$ \\
Microsome (5) & Glucose, 3 h & $0.25 \pm 0.03$ & $0.65 \pm 0.08$ & $0.90 \pm 0.09$ & 0.38 & $0.46 \pm 0.04$ \\
Microsome (5) & Ethanol, 1 wk & $0.36 \pm 0.02$ & $0.40 \pm 0.08$ & $0.75 \pm 0.09$ & 0.89 & $0.76 \pm 0.10 \pm \ddagger$ \\
Microsome (5) & Glucose, 1 wk & $0.27 \pm 0.04$ & $0.66 \pm 0.14$ & $0.93 \pm 0.16$ & 0.42 & $0.43 \pm 0.08$ \\
\hline
\end{tabular}

* All rates are expressed as the nanomoles of $s n\left[1,3-{ }^{1+} \mathrm{C}\right]$ glycerol-3-phosphate incorporated into the indicated glycerolipid (NL, neutral lipid; PL, phospholipid; total $=\mathrm{PL}+\mathrm{NL}$ ) per min per milligram protein \pm SEM.

$\$$ Total glycerolipid formation is a measure of $s n$-glycerol-3-phosphate acyltransferase activity.

$\$$ The NL/PL ratio is an indirect measure of phosphatidate phosphohydrolase activity.

"Microsomal phosphatidate phosphohydrolase activity was measured as described in Methods using membrane-bound phosphatidic acid as substrate. Reaction rates are expressed as the nanomoles of phosphatidic acid incorporated into diglyceride per minute per milligram of microsomal protein.

Number in parentheses indicates the number of hamsters in each group.

** $P \leq 0.01$ level of significance from glucose control.

$\sharp P \leq 0.05$ level of significance from glucose control. 


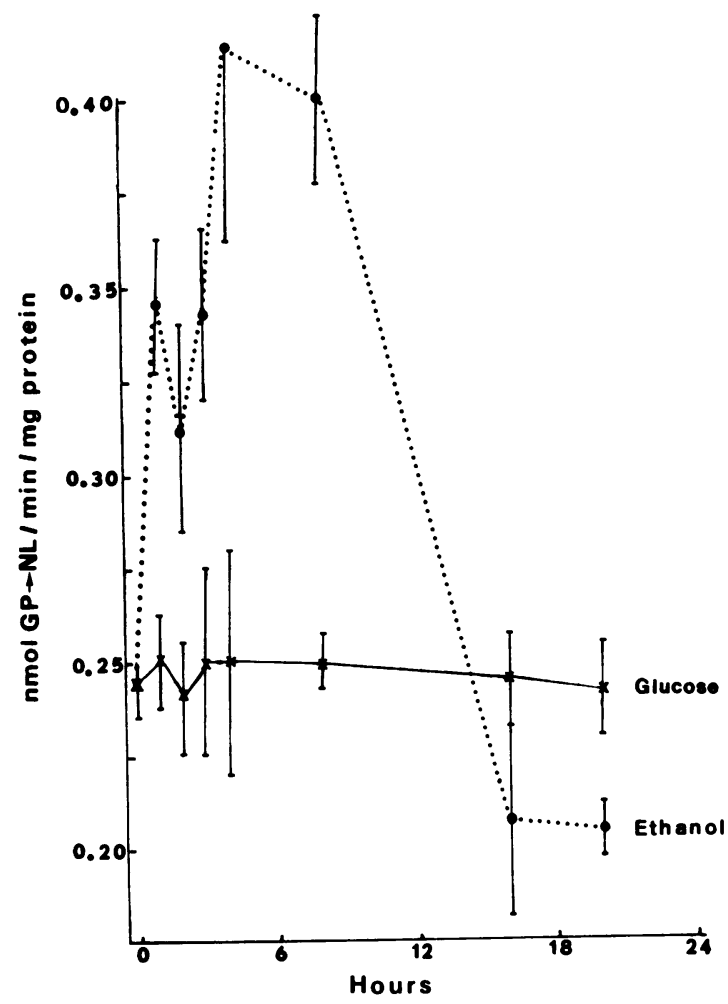

FIgURE 4 The incorporation of $s n\left[1,3-{ }^{14} \mathrm{C}\right]$ glycerol-3-phosphate (GP) into neutral (NL) glycerolipids by hamster liver microsomes isolated from animals receiving a single dose of ethanol $(5 \mathrm{~g} / \mathrm{kg})$ or glucose $(8.75 \mathrm{~g} / \mathrm{kg})$ for various time periods. Each point represents the mean of four to five animals and the brackets indicate the SEM.

The results presented here support these observations. Several previous studies indicated that alcohol consumption increased hepatic $(3,5,6,9-15)$ and intestinal (29-31) triglyceride production. However, the mechanism by which ethanol elevates glyceride formation is not clear. Increases in hepatic fatty acid and $s n$-glycerol-3-phosphate concentrations may provide substrate for the rise in hepatic triglyceride formation in vivo $(3,7,9,10,12,17,18,32)$. However, the rise in hepatic glycerolipid formation measured in vitro, as reported here and previously (11-14), indicates that ethanol intake also increases the capacity to synthesize glycerolipids by liver. The greater rise in glycerolipid formation (Figs. 4 and 5) than in hepatic triglyceride content (Table I) is not surprising because serum triglyceride levels also are elevated (Table I), presumably by increased release of very low density lipoprotein from liver.

The major pathway of hepatic glycerolipid biosynthesis is the $s n$-glycerol-3-phosphate pathway (33). Optimum rates in vitro for each reaction of this pathway in rat liver microsomes have been determined (25). The latter studies indicate that two en- zymes, $s n$-glycerol-3-phosphate acyltransferase and phosphatidate phosphohydrolase are rate-limiting in the formation and metabolism of phosphatidic acid, respectively. Joly et al. (13) noted that chronic ethanol intake of $>24 \mathrm{~d}$ elevated hepatic microsomal $s n$ glycerol-3-phosphate acyltransferase activity by $73 \%$. Our studies (14), however, indicate that acute and chronic ethanol feeding does not cause a significant rise in microsomal $s$-glycerol-3-phosphate acyltransferase activity as measured by our methods. This discrepancy may be attributed to differences in experimental techniques and animal models. In contrast, microsomal and supernatant phosphatidate phosphohydrolase showed alterations in activity that correlated well with ethanol-induced increases in hepatic triglyceride formation as measured both in vivo and in vitro. Other investigators have also demonstrated that acute ethanol intake increases hepatic supernatant phosphatidate phosphohydrolase activity $(11,12)$. At present, it is uncertain whether microsomal and supernatant phosphatidate phosphohydrolase activities are distinct enzymes. The differ-

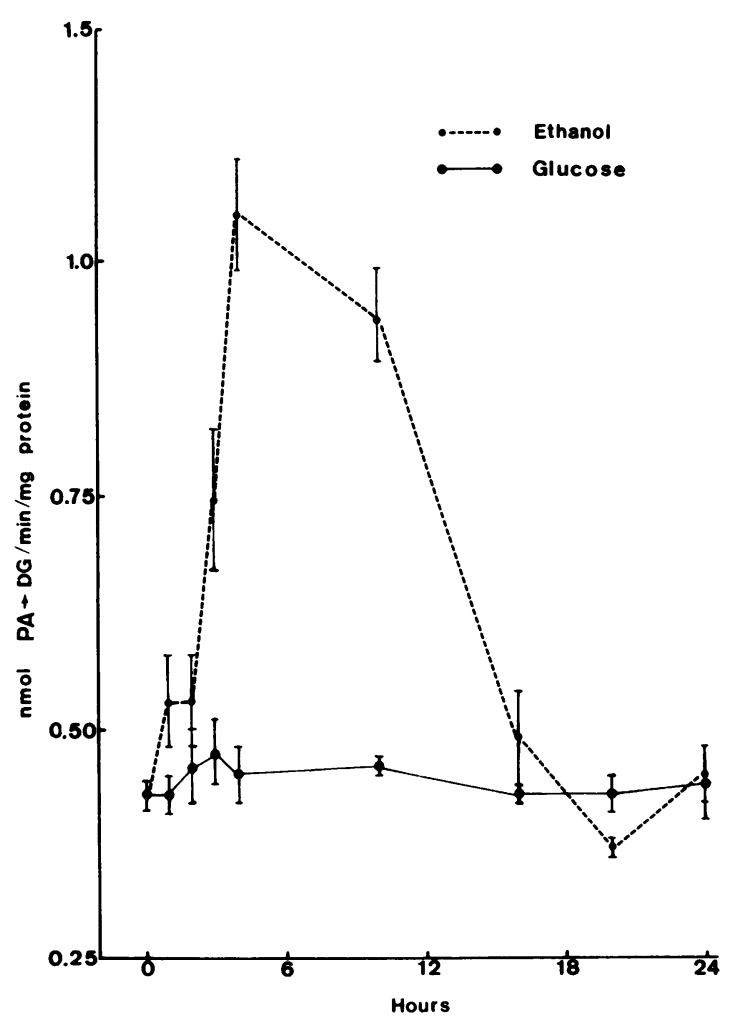

Figure 5 The conversion of labeled membrane-bound phosphatidic acid (PA) to diglyceride (DG) by microsomes isolated from livers of hamsters exposed to a single dose of ethanol $(5 \mathrm{~g} / \mathrm{kg})$ or glucose $(8.75 \mathrm{~g} / \mathrm{kg})$ for various time periods. Each determination represents the mean of four to five animals and the SEM is indicated by the brackets. 
ences in enzyme characteristics reported previously from this laboratory (25) may have resulted from release of the enzyme from the lipid environment of the microsomal membrane. Alternatively, the two activities could have different specificities or functions as yet unrecognized. Nevertheless, both supernatant and microsomal phosphatidate phosphohydrolase showed similar increases in activity after ethanol administration, which is consistent with other evidence that phosphatidate phosphohydrolase is important in the regulation of hepatic triglyceride formation during high sugar intake $(26,33)$, fasting (34), hepatectomy (35), obesity (36), diabetes (37), toxin exposure $(38,39)$, and exposure to lipid-lowering agents $(21,40)$. Hence, phosphatidate phosphohydrolase appears to possess characteristics of a ratecontrolling reaction because $(a)$ it regulates a branch point between phospholipid and triglyceride biosynthesis; $(b)$ it has a lower reaction rate in vitro than other enzymes involved in glycerolipid biosynthesis; and $(c)$ it exhibits rapid responses in activity under various physiological and nutritional conditions.

At present, the mechanism of the ethanol-induced increase in phosphatidate phosphohydrolase is unknown. The rapid rise in activity with acute ethanol intake $(4 \mathrm{~h})$ suggests that either phosphatidate phosphohydrolase content rapidly increases or a preexisting enzyme is activated.

Recent studies (41) using hepatocyte monolayers indicate that cells exposed to ethanol in vitro also demonstrate a significant rise in phosphatidate phosphohydrolase activity. Ethanol-induced increases in hepatocyte phosphatidate phosphohydrolase activity are reduced by simultaneously exposing hepatocyte monolayers to either pyrazole or cycloheximide. These results suggest that a metabolite of ethanol increases phosphatidate phosphohydrolase activity, and the rise in enzymatic activity may be a result of an increase in enzyme content. The latter hypothesis is supported by the observation of Mangiapane et al. (35) that actinomycin $\mathrm{D}$ administration can block the rise in hepatic phosphatidate phosphohydrolase activity after partial hepatectomy.

\section{ACKNOWLEDGMENTS}

The excellent technical assistance of David Borzelleca, Barbara Landa, Courtney Ludeman, and Earl Tyree is gratefully acknowledged. The typing assistance of Nancy Couleman is also appreciated.

This research was supported by U. S. Public Health Service grants HL 16464, AM 18976, and 5 S07 RR0 5430.

\section{REFERENCES}

1. Nestel, P. J., and E. Z. Hirisch. 1965. Mechanism of alcohol induced hypertriglyceridemia. J. Lab. Clin. Med. 66: $357-365$.
2. Jones, D. P., E. S. Perman, and C. F. Lieber. 1965. Free fatty acid turnover and triglyceride metabolism after ethanol ingestion in man. J. Lab. Clin. Med. 66: 804-813.

3. Lieber, C. S. 1974. Effect of ethanol upon lipid metabolism. Lipids. 9: 103-116.

4. Hernell, O., and O. Hohnson. 1973. Effect of ethanol on plasma triglycerides in male and female rats. Lipids. 8: 503-508.

5. Mendenhall, C. L., R. H. Bradford, and R. H. Furman. 1969. Effect of ethanol on glycerolipid metabolism in rat liver. Biochim. Biophys. Acta. 187: 501-509.

6. Barona, E., and C. S. Lieber. 1970. Effects of chronic ethanol feeding on serum lipoprotein metabolism in the rat. J. Clin. Invest. 49: 769-778.

7. Ylikahri, R. 1970. Ethanol-induced changes in hepatic $\alpha$-glycerophosphate and triglyceride concentration in normal and thyroxine-treated rat. Metab. Clin. Exp. 19: 1036-1045.

8. Barboriak, J. J. 1966. Effect of ethanol on lipoprotein lipase activity. Life Sci. 5: 237-241.

9. Nikkila, E. A., and K. Ojala. 1963. Ethanol-induced alterations in the synthesis of hepatic and plasma lipids and hepatic glycogen from glycerol-C ${ }^{14}$. Life Sci. 10: 717-721.

10. Scheig, R, and K. J. Isselbacher. 1965. Pathogenesis of ethanol-induced fatty liver. III. In vivo and in vitro effects of ethanol on hepatic fatty acid metabolism in rat. J. Lipid Res. 6: 269-277.

11. Savolainen, M. J. 1977. Stimulation of hepatic phosphatidate phosphohydrolase activity by a single dose of ethanol. Biochem. Biophys. Res. Commun. 75: 511-518.

12. Pritchard, P. H., M. Bowley, S. L. Burditt, J. Cooling, H. P. Glenny, N. Lawson, R. G. Sturton, and D. N. Brindley. 1977. The effects of acute ethanol feeding and of chronic benflourex administration on the activities of some enzymes of glycerolipid synthesis in rat liver and adipose tissue. Biochem. J. 166: 639-642.

13. Joly, J. G., L. Fienman, H. Ishii, and C. S. Lieber. 1973. Effect of chronic ethanol feeding on hepatic microsomal glycerophosphate acyltransferase activity. J. Lipid Res. 14: 337-343.

14. Lamb, R. G., and H. J. Fallon. 1977. Effects of acute and chronic ethanol intake on hepatic glycerolipid biosynthesis. Fed. Proc. 36: 286A (Abstr.).

15. Wood, C. K., and R. G. Lamb. 1977. Effects of ethanol on glycerolipid metabolism in primary monolayer cultures of adult rat hepatocytes. Fed. Proc. 36: 286.

16. Mendenhall, C. L., R. H. Bradford, and R. H. Furman. 1969. Effect of ethanol on fatty acid composition of hepatic phosphatidylcholine and phosphatidylethanolamine and on microsomal fatty acyl-CoA: Lysophosphatide transferase activities in rats fed corn oil or coconut oil. Biochim. Biophys. Acta. 187: 510-519.

17. Nikkila, E. A., and K. Ojala. 1963. Role of hepatic L- $\alpha$ glycerophosphate and triglyceride synthesis in production of fatty liver by ethanol. Proc. Soc. Exp. Biol. Med. 113: 814-817.

18. Guynn, R. W., D. Veloso, R. L. Harris, J. W. R. Lawson, and R. L. Veech. 1973. Ethanol administration and the relationship of malonyl-coenzyme A concentrations to the rate of fatty acid synthesis in rat liver. Biochem. J. 136: 639-647.

19. Thompson, J. A., and R. C. Reitz. 1976. Studies on the acute and chronic effects of ethanol ingestion on choline oxidation. Ann. N.Y. Acad. Sci. 273: 194-204.

20. Adams, L. L., W. W. Webb, and H. J. Fallon. 1971. 
Inhibition of hepatic triglyceride formation by clofibrate. J. Clin. Invest. 50: 2339-2346.

21. Lamb, R. G., S. D. Wyrick, and C. Piantadosi. 1977. Hypolipidemic activity of in vitro inhibitors of hepatic and intestinal sn-glycerol-3-phosphate acyltransferase and phosphatidate phosphohydrolase. Atherosclerosis. 27: $147-154$.

22. Lamb, R. G., and H. J. Fallon. 1970. The formation of monoacylglycerophosphate from sn-glycerol-3-phosphate by a rat liver particulate fraction. J. Biol. Chem. 245: 3075-3083.

23. Fallon, H. J., J. Barwick, R. G. Lamb, and H. van den Bosch. 1975. Studies of rat liver microsomal diglyceride acyltransferase and choline phosphotransferase using microsomal-bound substrate: Effects of high fructose intake. J. Lipid Res. 16: 107-115.

24. Lamb, R. G., C. K. Wood, B. M. Landa, P. S. Guzelian, and H. J. Fallon. 1977. Studies of the formation and release of glycerolipids by primary monolayer cultures of adult rat hepatocytes. Biochim. Biophys. Acta. 489: 318-329.

25. Lamb, R. G., and H. J. Fallon. 1974. Glycerolipid formation from sn-glycerol-3-phosphate by rat liver cell fractions: The role of phosphatidate phosphohydrolase. Biochim. Biophys. Acta. 348: 166-178.

26. Lamb, R. G., and H. J. Fallon. 1974. An enzymatic explanation for dietary induced alterations in hepatic glycerolipid metabolism. Biochim. Biophys. Acta. 348: 179-188.

27. Haux, P., and S. Natelson. 1971. Microprocedures for serum triglyceride estimation. Microchem. J. 16: 68-76.

28. Lowry, O. H., A. L. Rosebrough, A. L. Farr, and R. J. Randall. 1951. Protein measurement with the Folin phenol-reagent. J. Biol. Chem. 193: 265-275.

29. Mistilis, S. P., and R. K. Ockner. 1972. Effects of ethanol on endogenous lipid and lipoprotein metabolism in small intestine. J. Lab. Clin. Med. 80: 34-46.

30. Carter, E. A., G. D. Drummey, and K. J. Isselbacher. 1971. Ethanol stimulates triglyceride synthesis by the intestine. Science (Wash. D. C.). 174: 1245-1247.

31. Barona, E., R. Pirola, and C. S. Lieber. 1975. Acute and chronic effects of ethanol on intestinal lipid metabolism. Biochim. Biophys. Acta. 388: 19-28.

32. Lieber, C. S., and R. Schmidt. 1961. The effect of ethanol on fatty acid metabolism stimulation of hepatic fatty acid synthesis. J. Clin. Invest. 40: 394-399.

33. Lamb, R. G., and H. J. Fallon. 1976. The effect of high sugar intake on the esterification of dihydroxyacetone phosphate by rat liver microsomes. J. Lipid Res. 17: 406-411.

34. Vavrecka, M., M. P. Mitchell, and G. Hubscher. 1969. The effect of starvation on the incorporation of palmitate into glycerides and phospholipids of rat liver homogenates. Biochem. J. 115: 139-145.

35. Mangiapane, E. H., K. A. Lloyd-Davies, and D. N Brindley. 1973. A study of some enzymes of glycerolipid biosynthesis in rat liver after subtotal hepatectomy. Biochem. J. 134: 103-112.

36. Fallon, H. J., R. G. Lamb, and S. C. Jamdar. 1977. Phosphatidate phosphohydrolase and the regulation of glycerolipid biosynthesis. Biochem. Soc. Trans. 5: 37-40.

37. Murthy, U. K., and J. C. Shipp. 1976. Evidence for increased biosynthesis of triglycerides (TG) in liver of diabetic rats. Abstracts of IX Congress of International Diabetes Foundation. 1: 64. (Abstr.)

38. Lamb, R. G., and W. L. Banks, Jr. 1977. Effects of hydrazine treatment on hepatic triglyceride biosynthesis. Pharmacologist. 19: 182. (Abstr.)

39. Lamb, R. G., and D. Perkins. 1978. The effect of carbon tetrachloride and phenobarbital exposure on rat liver triglyceride biosynthesis. Pharmacologist. 20: 188. (Abstr.)

40. Brindley, D. N., and M. Bowley. 1975. Drugs affecting the synthesis of glycerides and phospholipids in rat liver. The effects of clofibrate, halofenate, fenfluramine, amphetamine, chincocaine, chlorpromazine, demethylimipramine, mepryamine and some of their derivatives. Biochem. J. 148: 461-469.

41. Wood, C. K., and R. G. Lamb. 1978. Effects of ethanol exposure in vivo and in vitro on glycerolipid biosynthesis of isolated, or primary monolayer cultures of, adult rat hepatocytes. Fed. Proc. 37: 420. (Abstr.) 